\title{
Microenvironment-driven resistance to B-Raf inhibition in a melanoma patient is accompanied by broad changes of gene methylation and expression in distal fibroblasts
}

\author{
ONDŘEJ KODET ${ }^{1-4}$, BARBORA DVOŘÁNKOVÁ ${ }^{1,3}$, BĚLA BENDLOVÁ ${ }^{5}$, VLASTA SÝKOROVÁ ${ }^{5}$, \\ IVANA KRAJSOVÁ ${ }^{4}$, JIŘÍ ŠTORK ${ }^{2,4}$, JAN KUČERA $^{1,2,4}$, PAVOL SZABO ${ }^{1,3}$, HYNEK STRNAD $^{6}$, \\ MICHAL KOLÁ $\check{R}^{6}$, ČESTMÍR VLČEK ${ }^{6}$, KAREL SMETANA Jr ${ }^{1,3}$ and LUKÁŠ LACINA ${ }^{1-4}$ \\ ${ }^{1}$ Institute of Anatomy and ${ }^{2}$ Department of Dermatology and Venereology, First Faculty of Medicine, \\ Charles University, 12808 Prague; ${ }^{3}$ BIOCEV, Biotechnology and Biomedicine Center of \\ The Academy of Sciences and Charles University in Vestec, 25250 Vestec; ${ }^{4}$ Department of Dermatology and Venereology, \\ General University Hospital, 12808 Prague; ${ }^{5}$ Institute of Endocrinology, 11694 Prague; \\ ${ }^{6}$ Institute of Molecular Genetics, Academy of Sciences of The Czech Republic, 14220 Prague, Czech Republic
}

Received July 27, 2017; Accepted January 18, 2018

DOI: $10.3892 /$ ijmm.2018.3448

\begin{abstract}
The incidence of malignant melanoma is rapidly increasing and current medicine is offering only limited options for treatment of the advanced disease. For B-Raf mutated melanomas, treatment with mutation-specific drug inhibitors may be used. Unfortunately, tumors frequently acquire resistance to the treatment. Tumor microenvironment, namely cancer-associated fibroblasts, largely influence this acquired resistance. In the present study, fibroblasts were isolated from a patient suffering from acrolentiginous melanoma (Breslow, $4.0 \mathrm{~mm}$; Clark, IV; B-Raf V600E mutated). The present study focused on the expression of structural and functional markers of fibroblast activation in melanoma-associated fibroblasts (MAFs; isolated prior to therapy initiation) as well as in autologous control fibroblasts (ACFs) of the same patient isolated during B-Raf inhibitor therapy, yet before clinical progression of the disease. Analysis of gene transcription was also performed, as well as DNA methylation status analysis at the genomic scale of both isolates. MAFs were positive for smooth muscle actin (SMA), which is a marker of myofibroblasts and
\end{abstract}

Correspondence to: Dr Lukáš Lacina, Institute of Anatomy, First Faculty of Medicine, Charles University, 3 U Nemocnice, 12800 Prague, Czech Republic

E-mail: lukas.lacina@lf1.cuni.cz

Abbreviations: ACF, autologous control fibroblasts; $\mathrm{CDF}$, control dermal fibroblasts; CT, computed tomography; MAF, melanoma associated fibroblasts; PCR, polymerase chain reaction; SMA, smooth muscle actin; TGF- $\beta 1$, transforming growth factor- $\beta 1$

Key words: melanoma, cancer-associated fibroblast, genome, transcriptome, gene methylation, stroma, smooth muscle actin, $\alpha$-actin-2, B-Raf inhibitor, transforming growth factor- $\beta 1$, stroma-driven resistance the hallmark of cancer stoma. Surprisingly, ACF isolated from the distant uninvolved skin of the same patient also exhibited strong SMA expression. A similar phenotype was also observed in control dermal fibroblasts (CDFs; from different donors) exclusively following stimulation by transforming growth factor (TGF)- $\beta 1$. Immunohistochemistry confirmed that melanoma cells potently produce TGF- $\beta 1$. Significant differences were also identified in gene transcription and in DNA methylation status at the genomic scale. Upregulation of SMA was observed in ACF cells at the protein and transcriptional levels. The present results support recent experimental findings that tumor microenvironment is driving resistance to B-Raf inhibition in patients with melanoma. Such an activated microenvironment may be viable for the growth of circulating melanoma cells.

\section{Introduction}

The incidence of malignant melanoma is increasing rapidly worldwide (1). Despite notable progress in melanoma research, treatment options for advanced stages of the disease remain limited and the mortality rate in advanced melanoma is significantly higher than in other skin tumors (1).

The tumor stroma represents an important component in the structure of malignant tumors. This microenvironment may significantly influence their biological properties, including metastatic potential (2). The powerful effect of this microenvironment has also been observed in malignant melanoma via convincing models, where melanoma cells acquired properties of melanocyte precursors (neural crest cells) following grafting to vertebrate embryos (3). The embryonic microenvironment here eliminates their ability to form tumors (3). Intercellular crosstalk between different cell types occurring in melanoma $(4,5)$ may be relevant for tumor biology in general.

As fibroblasts represent a fundamental component of various tissues, they also have an indispensable role in cancer (2). 
The broad biological activity of melanoma-associated fibroblasts (MAFs) has been described and notably, they are also able to stimulate other cancer types than melanoma in vitro $(4,6-9)$. MAFs, as well as other cancer-associated fibroblasts, express smooth muscle actin (SMA) $(10,11)$ in the majority of tumor types (2). The transition of fibroblasts to SMA-expressing myofibroblasts is primarily stimulated by transforming growth factor- $\beta 1$ (TGF- $\beta 1$ ), which is frequently elevated in sera of melanoma patients. An additive effect of endogenous lectin, galectin-1, has also been reported in this context (10-12).

The present report details the comparison of MAFs prepared from a cutaneous melanoma metastasis and autologous control fibroblasts (ACF) from non-cancerous skin of the same patient. The former was isolated prior to therapy initiation, and the latter was isolated during B-Raf inhibitor therapy, yet before the onset of computed tomography (CT)-documented disease progression. Such a matched pair of stromal fibroblasts of human origin is notably rare for analysis. The data obtained from cell cultures are compared with immunohistochemical analysis of sections from the melanoma metastasis including the expression of TGF- $\beta 1$. The effect of this cytokine on normal dermal fibroblasts prepared from the skin of healthy donors was also examined.

\section{Material and methods}

Case report, tissue collection and processing. The patient, a 76 year-old Caucasian female who was diagnosed with acrolentiginous melanoma of the left sole (Breslow, $4.0 \mathrm{~mm}$; Clark, IV) (13) in 2004, was recruited in January 2011 at the Department of Dermatology and Venereology, First Faculty of Medicine, Charles University (Prague, Czech Republic). CT scanning was used throughout observation of the patient (Fig. 1), and 7 years following wide surgical excision, multiple metastases were detected on the lateral parts of the chest and in axillary lymph nodes (Fig. 1A). One cutaneous metastasis on the chest was surgically removed for histologic confirmation (Figs. 1A and 2) of the disease relapse and also for B-Raf V600E mutation screening. MAFs were isolated from the same tumor mass using a previously described method $(14,15)$. B-Raf V600E mutation was confirmed (Fig. 3) and treatment with the B-Raf inhibitor vemurafenib was initiated. Following 3 months of vemurafenib therapy, unaffected skin from the anatomically comparable site (Fig. 1B) was harvested via punch biopsy to isolate ACFs. At this stage, partial response was achieved using RECIST criteria (16). Following further 6 months, CT documented rapid disease progression and the patient succumbed to mortality 5 months later.

Control dermal fibroblasts (CDF) were prepared from anatomically comparable chest skin of three healthy Caucasian women donors (aged 35-42 years), undergoing aesthetic surgery (recruited at the same department between March 2011 and September 2013). All tissue samples used in the present study were obtained following the provision of explicit written informed consent, with a protocol reviewed by a local ethics committee (FWA 00003027; General University Hospital, Prague, Czech Republic) with full respect to the Declaration of Helsinki. Institutional consent for publication and data maintenance was also issued.
Cell culture. MAFs, ACFs and CDFs were isolated from tissue samples as described previously $(14,15)$. Passage 3 or 4 cells were used in the present study for analysis. For immunocytochemistry, RNA and DNA studies, fibroblasts were cultured for 5 days before they reached subconfluent monolayers in Dulbecco's modified Eagle's medium containing 10\% fetal bovine serum and antibiotics (penicillin/streptomycin; $10.0 \mathrm{U} / \mathrm{ml}$ and $10.0 \mu \mathrm{g} / \mathrm{ml}$, respectively; all, Biochrom, Ltd., Cambridge, $\mathrm{UK}$ ) at $37^{\circ} \mathrm{C}$ and $5 \% \mathrm{CO}_{2}$. To evaluate the induction of SMA in CDF, TGF- $\beta 1$ (R\&D Systems, Inc., Minneapolis, MN, USA) was supplemented to the culture medium at $10 \mathrm{ng} / \mathrm{ml}(11)$.

$B$-Raf sequencing. For DNA extraction, paraffin-embedded formalin-fixed (4\% formaldehyde in PBS for 24-48 $\mathrm{h}$ at room temperature) tissue sections (thickness, $5 \mu \mathrm{m}$ ) were deparaffinized using sequential washes with xylene and absolute ethanol. Sections were digested using proteinase $\mathrm{K}$ and DNA was extracted using NucleoSpin FFPE DNA (both, Machery-Nagel GmbH, Düren, Germany), according to the manufacturer's protocol. DNA extraction from fibroblasts was performed using TRIzol reagent (Invitrogen; Thermo Fisher Scientific, Inc., Waltham, MA, USA) according to the manufacturer's protocol. The concentration of DNA was measured using a fluorometer Qubit 2.0 (Invitrogen; Thermo Fisher Scientific, Inc.).

DNA extracted from MAFs was selectively amplified to generate a 224-bp sequence of $B R A F$ exon 15 using polymerase chain reaction (PCR) with the following primers: Forward, 5'-TCATAATGCTTGCTCTGATAGGA-3' and reverse, 5'-GGCCAAAAATTTAATCAGTGGA-3' (15). A total of $30 \mathrm{ng}$ DNA was amplified with $0.1 \mu \mathrm{M}$ each primer, $160 \mu \mathrm{M}$ deoxynucleotide triphosphates, $2 \mathrm{mM} \mathrm{MgCl}_{2}, 0.3 \mathrm{U}$ Gold AmpliTaq Perkin Polymerase, and 1X PCR Buffer II $(10 \mathrm{mM}$ Tris- $\mathrm{HCl} \mathrm{pH} 8.3,50 \mathrm{mM} \mathrm{KCl})$ in a final volume of $15 \mu \mathrm{l}$ (both from Thermo Fisher Scientific, Inc). Cycling conditions were as follows: Denaturation step at $94^{\circ} \mathrm{C}$ for $2 \mathrm{~min}$ and at $95^{\circ} \mathrm{C}$ for $20 \mathrm{sec}$ followed by 5 cycles of denaturation at $95^{\circ} \mathrm{C}$ for $20 \mathrm{sec}$, annealing at $62.5^{\circ} \mathrm{C}$ for $30 \mathrm{sec}$ and primer extension at $72^{\circ} \mathrm{C}$ for $1 \mathrm{~min} ; 35$ cycles of denaturation at $95^{\circ} \mathrm{C}$ for $20 \mathrm{sec}$, annealing at $57.5^{\circ} \mathrm{C}$ for $30 \mathrm{sec}$ and primer extension at $72^{\circ} \mathrm{C}$ for $1 \mathrm{~min}$; and one final run-off extension at $72^{\circ} \mathrm{C}$ for $10 \mathrm{~min}(16)$. PCR was performed in a TGradient 96 thermocycler (Biometra GmbH, Göttingen, Germany). PCR products were visualized via $1.5 \%$ agarose gel electrophoresis in 0.5X Tris-borate-EDTA buffer (Thermo Fisher Scientific, Inc). Subsequently, the PCR products were purified using an Agencourt AMpure XP (Beckman Coulter, Inc., Brea, CA, USA) and sequenced using forward primers of the PCR amplification and a DTCS Quick Start kit according to the manufacturer's protocol (Beckman Coulter, Inc). The cycle sequencing conditions consisted of 30 cycles of $96^{\circ} \mathrm{C}$ for $20 \mathrm{sec}, 50^{\circ} \mathrm{C}$ for $20 \mathrm{sec}$, and $60^{\circ} \mathrm{C}$ for $4 \mathrm{~min}$. The PCR products were re-purified using an Agencourt CleanSEQ kit (Beckman Coulter, Inc.) according to the manufacturer's protocols, sequenced on a CEQ 8000 sequencing machine (Beckman Coulter, Inc.), and analysed using CEQ 8000 sequencing software. Sequence traces were compared with $B R A F$ reference sequence (NM_004333.4; https://www.ncbi. nlm.nih.gov/nuccore/NM_004333). 

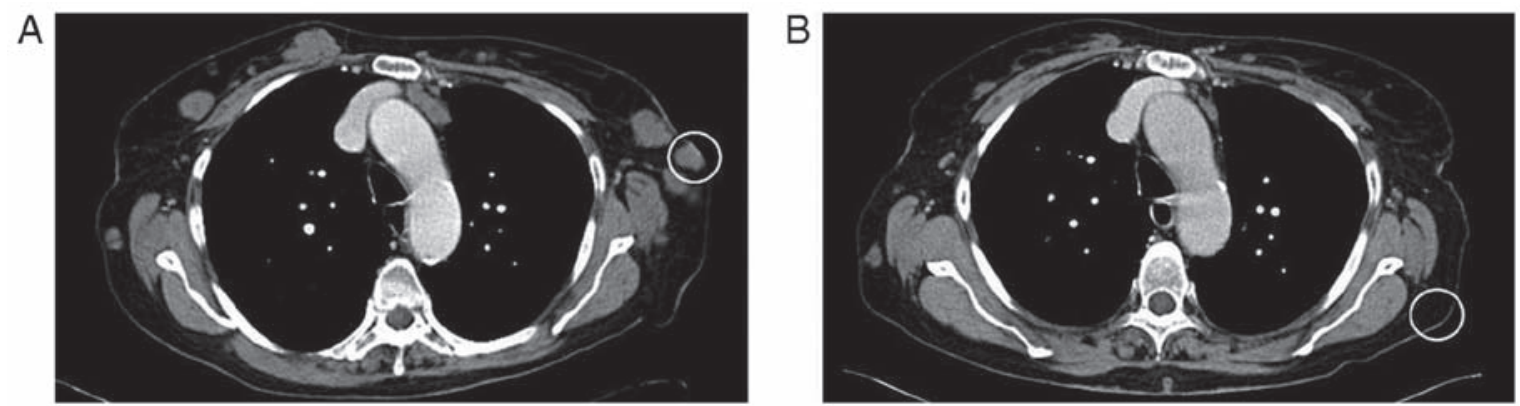

Figure 1. CT scan of the patient's chest. (A) Skin metastasis of melanoma used for the analysis (white circle). (B) Control CT scan after 3 months on vemurafenib treatment; distant uninvolved skin (white circle), a biopsy from this site was used for isolation of autologous control fibroblasts. CT, computed tomography.
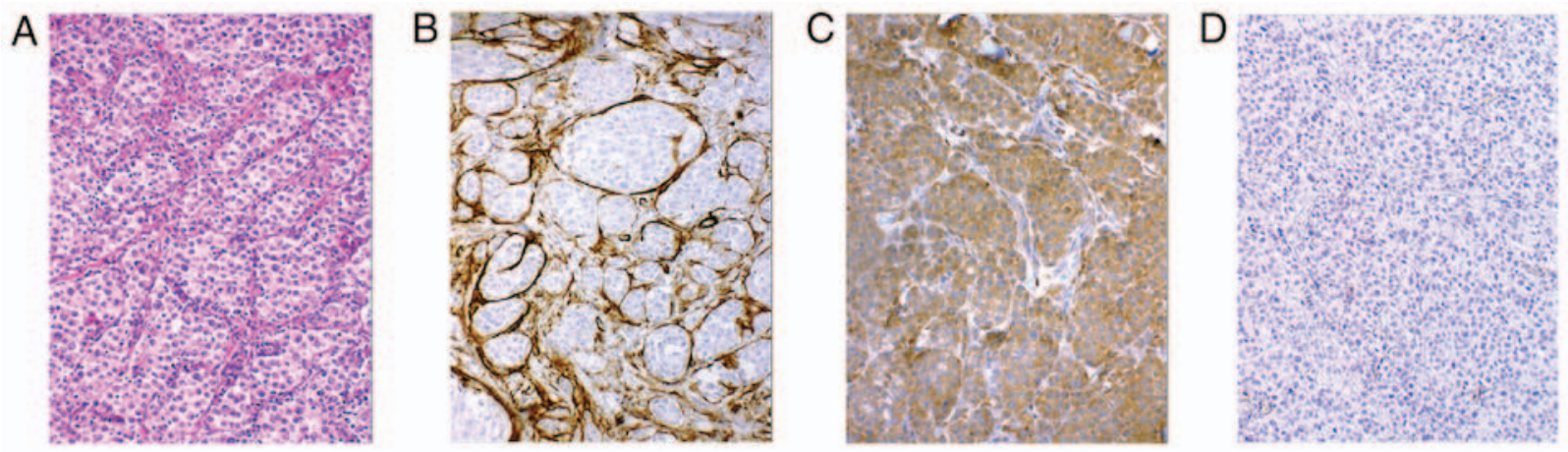

Figure 2. (A) Histology of malignant melanoma metastasis (biopsy from Fig. 1A) with hematoxylin and eosin staining; magnification, x200. (B) Immunohistochemical analysis (hematoxylin counterstained) confirmed smooth muscle actin-positive myofibroblasts (brown) of tumor stroma between tumor lobules and also (C) transforming growth factor $\beta 1$ intensely positive melanoma cells in the lobules of melanoma metastasis. (D) Negative control.

Immunohistochemistry and immunocytochemistry. Immunohistochemistry was routinely performed using the avidin-biotin complex method. Briefly, tissue was fixed for $24-48 \mathrm{~h}$ in $4 \%$ formaldehyde (in PBS) at room temperature and embedded in paraffin. Tissue sections (5-um tick; rehydrated through xylene and ethanol) were washed with PBS with $0.2 \%$ Tween-20, and heat-induced epitope retrieval was performed in citrate buffer (pH 6.0, in autoclave at $120^{\circ} \mathrm{C}$ for 3 min with slow gradual cooling for $60 \mathrm{~min}$. All chemicals for immunohistochemistry were supplied by Sigma-Aldrich (Merck KGaA, Darmstadt, Germany). Tissue sections were blocked using Protein Block system (Dako; Agilent Technologies, Inc., Santa Clara, CA, USA; cat. no. X0909) at room temperature for $10 \mathrm{~min}$ according to the manufacturer's protocol, followed by $3 \%$ hydrogen peroxide (in PBS) treatment for 20 min (all from Sigma-Aldrich; Merck KGaA). Consequently sections were incubated overnight at $4^{\circ} \mathrm{C}$ with biotinylated antibodies directed against SMA (1:100; Dako; Agilent Technologies, Inc.; cat. no. M0851; clone 1A4), and TGF- $\beta 1$ (1:100, Bioss Antibodies, Inc., Woburn, MA, USA; cat. no. bs-0086). A Dako Streptavidin Peroxidase kit (including 50X 3,3'-diaminobenzidinehorseradish peroxidase substrate buffer) was used for visualization of immunohistochemical reaction according to the manufacturer's protocol (Dako; Agilent Technologies, Inc.; cat. no. K5001). Nuclei were counterstained with hematoxylin and mounted in permanent mountant.

The cultured cells on coverslips were briefly fixed in $2 \%$ paraformaldehyde in PBS for $5 \mathrm{~min}$ at room temperature and permeabilized with Triton X-100 (Sigma-Aldrich;
A

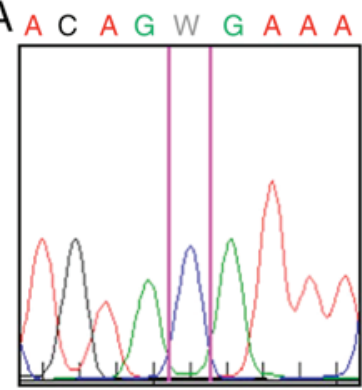

$\mathrm{B}$

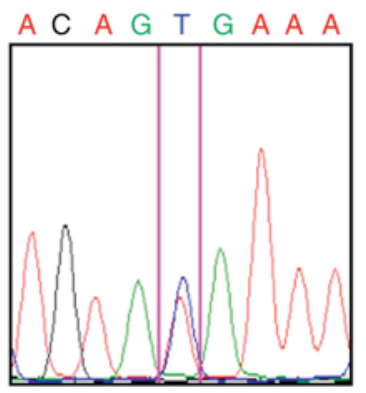

Figure 3. (A) B-Raf V600E mutation was not detected in melanoma-associated fibroblasts. (B) However, this mutation was confirmed in the same metastasis. W denotes $\mathrm{A} / \mathrm{T}$ mutation.

Merck KGaA). Antibodies against SMA (1:100; mouse monoclonal; Dako; Agilent Technologies, Inc., cat.no. M0851; clone 1A4) and fibronectin (1:1,000; rabbit polyclonal; Dako; Agilent Technologies, Inc.; cat. no. A0245) were used to detect protein levels, via incubations for $2 \mathrm{~h}$ at room temperature. Blocking was performed in $10 \%$ goat serum for $30 \mathrm{~min}$ at room temperature. Results of immunocytochemical reaction were visualized using tetramethylrhodamine-conjugated goat anti-rabbit (cat. no. T5393; 1:250) and fluorescein isothiocyanate-conjugated goat anti-mouse antibody (cat. no. AP307F; 1:250; both, Sigma-Aldrich; Merck KGaA) for $60 \mathrm{~min}$ at room temperature). Nuclei were counterstained with DAPI for $1 \mathrm{~min}$ at room temperature (Sigma-Aldrich; Merck KGaA). 

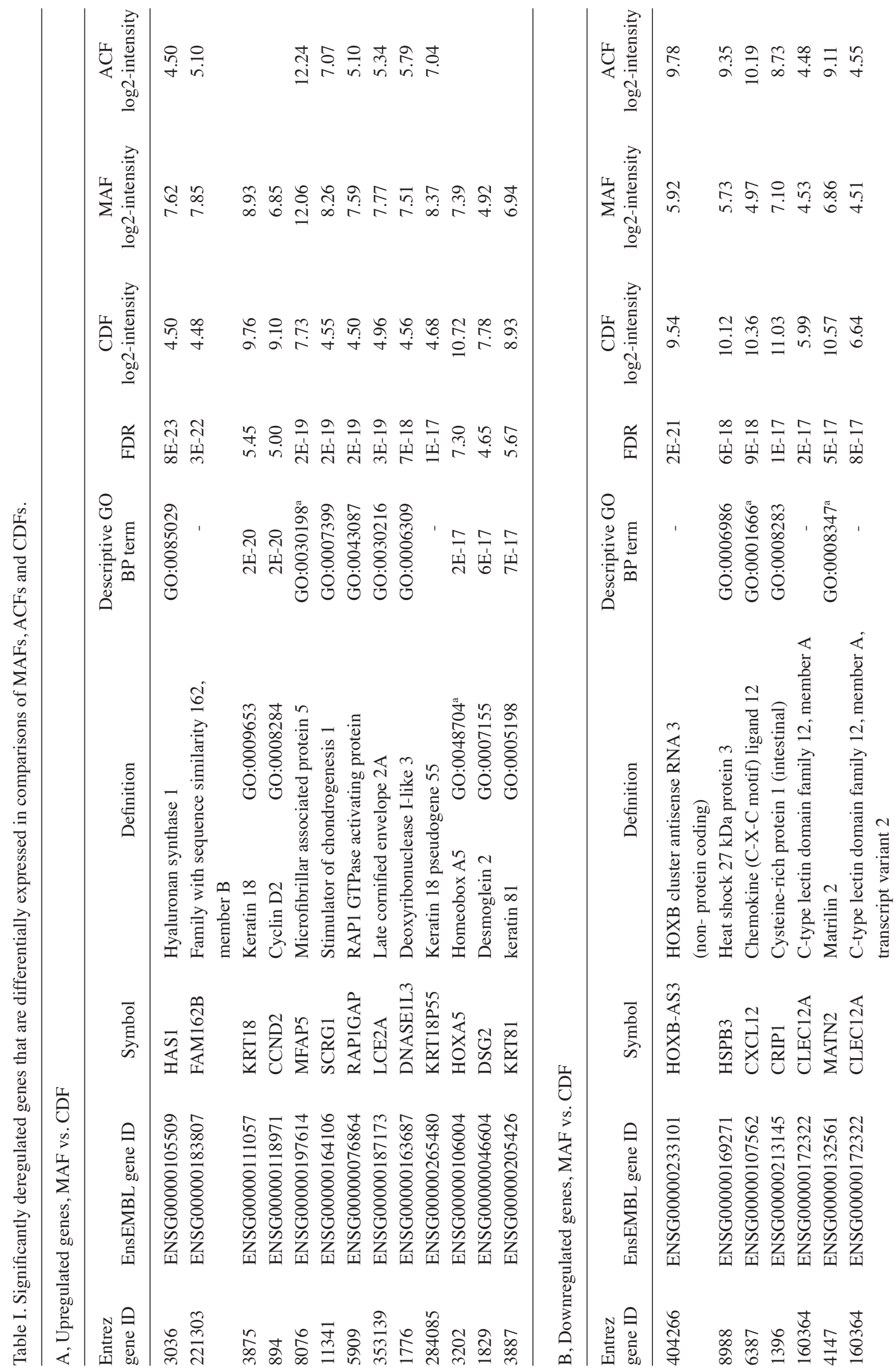


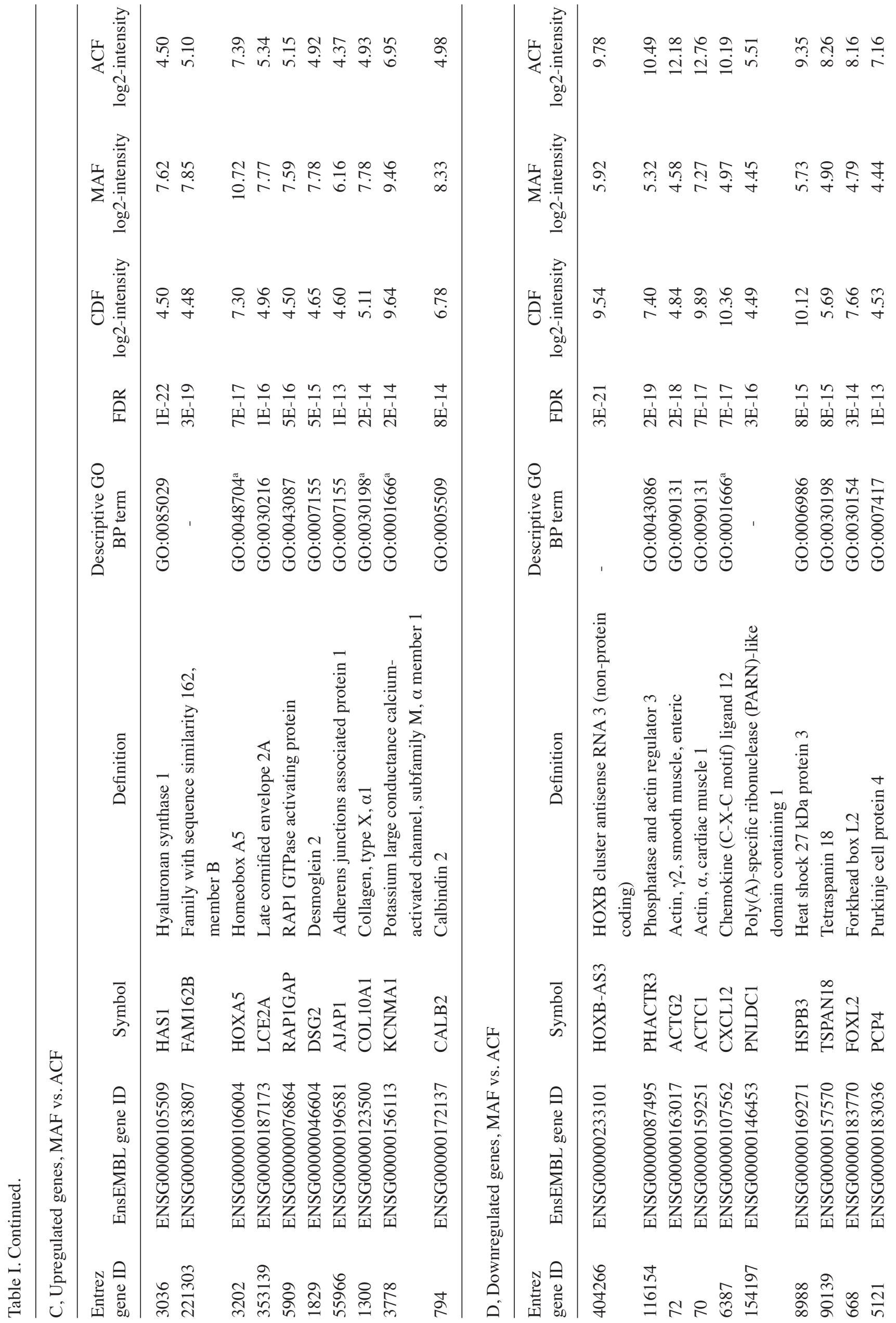




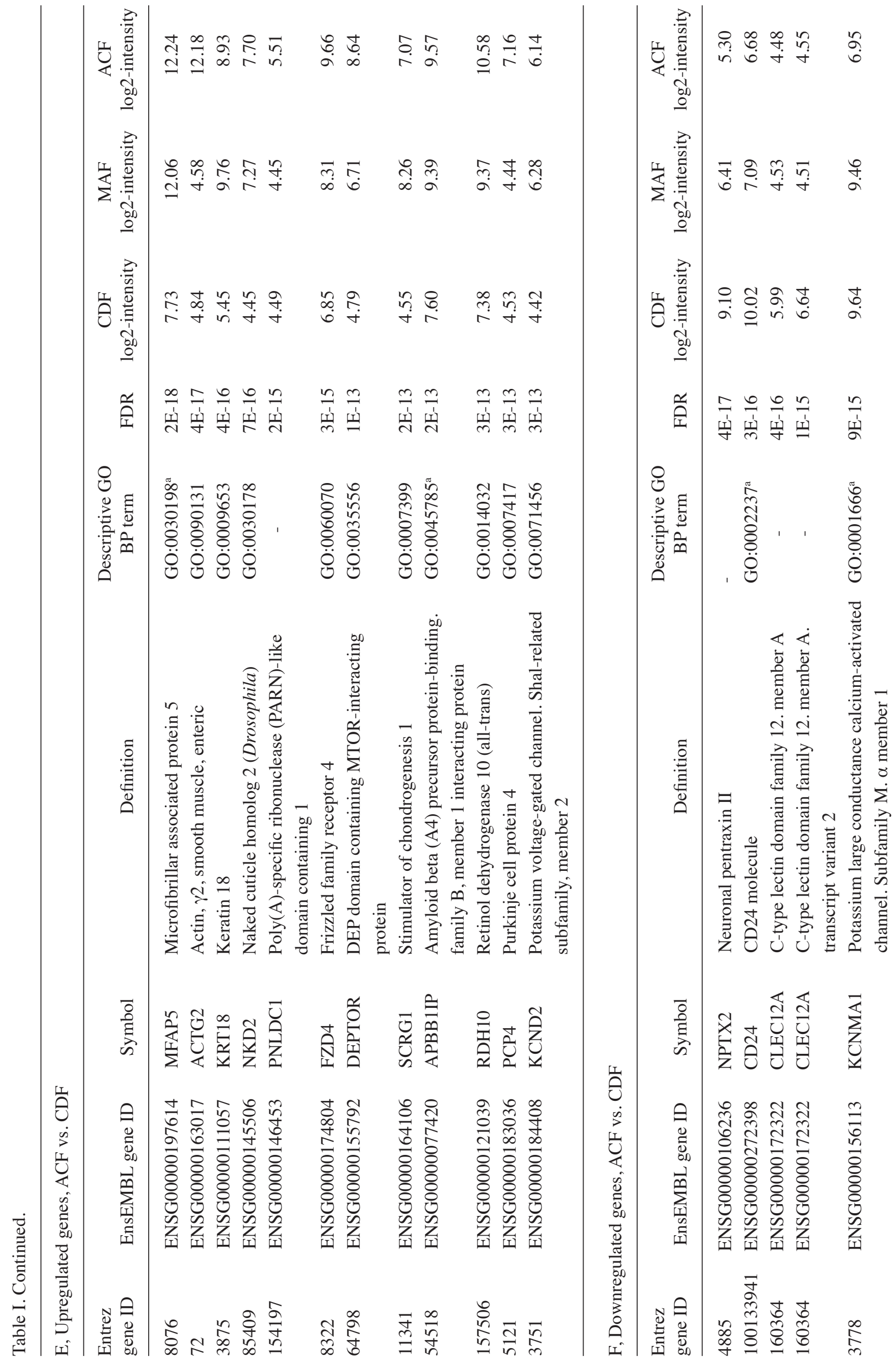


The negative control of all staining procedures was performed by replacement of primary antibody with appropriate isotype control (Universal Negative Control; mouse cat. no. N1698; rabbit cat. no. N1699; Dako; Agilent Technologies, Inc.). Following mounting in Vectashield (Vector Laboratories, Inc., Burlingame, CA, USA) samples were analyzed at x200 magnification using an ECLIPSE-90i fluorescence microscope (Nikon Corp., Tokyo, Japan) equipped with suitable filter blocks, a charge-couple device camera (Vosskühler, Osnabrück, Germany) and a system for computer-assisted image analysis (LUCIA 5.1, Laboratory Imaging s.r.o., Prague, Czech Republic).

Transcriptome analysis. Total RNA was isolated from MAFs, ACFs and CDFs using an RNeasy Micro kit (Qiagen Sciences, Inc., Gaithersburg, MD, USA) according to the manufacturer's protocol. Quality and concentration of RNA were measured with a NanoDrop 2000 spectrophotometer (Thermo Fisher Scientific, Inc.). RNA integrity was analysed using an Agilent Bioanalyzer 2100 (Agilent Technologies, Inc.). Only samples with an intact RNA profile were used for expression profiling analyses (RNA Integrity Number $>9$ ).

Illumina HumanHT-12 v4 Expression BeadChips (Illumina, Inc., San Diego, CA, USA) were used for the microarray analysis following the standard protocol. Briefly, 200 ng RNA was amplified with the Illumina TotalPrep RNA Amplification kit (Ambion; Thermo Fisher Scientific, Inc.) and 750 ng labelled RNA was hybridized on the chip according to the manufacturer's protocol. Analysis was performed in four (CDF, 2 donors) and two (MAF and ACF) replicates per group. The raw data were preprocessed using GenomeStudio software (version 1.9.0.24624; Illumina, Inc.) and the limma package (19) of Bioconductor (20), as described previously (21). The transcription profiles were background corrected using a normal-exponential model, quantile normalized and variance stabilized using base 2 logarithmic transformation. Moderated t-test was used to detect differentially expressed transcripts within limma (19). False discovery rates (FDR) were used to select significantly differentially transcribed genes (FDR <0.05), as presented in Table I. Principal components analysis (PCA) was performed using the made4 (22) package of the Bioconductor on expression data of the genes that were found differentially expressed in at least one of the comparisons.

Genome methylation analysis. Genomic DNA was isolated using the aforementioned standard techniques and purified using a Qiagen DNeasy kit (Qiagen Sciences, Inc.) according to the manufacturer's protocol. Quality and concentration of DNA were measured with a NanoDrop 1000 spectrophotometer (Thermo Fisher Scientific, Inc.). Bisulfite conversion was performed using an EZ DNA Methylation kit (Zymo Research Corp., Irvine, CA, USA).

Illumina Infinium HumanMethylation27 BeadChips (Illumina, Inc.) were used for microarray analysis following the manufacturer's protocol. In brief, $400 \mathrm{ng}$ bisulphite-converted DNA was amplified using an Infinium Methylation Assay kit (Illumina, Inc.) and $750 \mathrm{ng}$ of labelled DNA was hybridized on the chip according to the manufacturer's procedure. The analysis was performed in two replicates per group (MAF, 
Table II. Results of gene set enrichment analysis performed on differentially expressed genes and GO BP terms.

$\mathrm{A},(\mathrm{MAF}$ and $\mathrm{ACF})$ vs. CDF

\begin{tabular}{|c|c|c|c|}
\hline GO BP ID & Term & Overlap & Adjusted P-value \\
\hline GO:0030198 & Extracellular matrix organization & $35 / 359$ & 0.00091 \\
\hline GO:0043062 & Extracellular structure organization & $35 / 360$ & 0.00091 \\
\hline GO:0001936 & Regulation of endothelial cell proliferation & $15 / 88$ & 0.00335 \\
\hline GO:0010574 & Regulation of vascular endothelial growth factor production & $8 / 27$ & 0.01791 \\
\hline GO:0002237 & Response to molecule of bacterial origin & $24 / 243$ & 0.01791 \\
\hline GO:0009611 & Response to wounding & $19 / 167$ & 0.01791 \\
\hline GO:0051272 & Positive regulation of cellular component movement & $27 / 296$ & 0.01791 \\
\hline GO:0040017 & Positive regulation of locomotion & $27 / 304$ & 0.02116 \\
\hline GO:2000147 & Positive regulation of cell motility & $26 / 287$ & 0.02116 \\
\hline GO:0001503 & Ossification & $15 / 116$ & 0.02116 \\
\hline GO:0008347 & Glial cell migration & $6 / 15$ & 0.02116 \\
\hline GO:0045765 & Regulation of angiogenesis & $19 / 179$ & 0.02490 \\
\hline GO:0032496 & Response to lipopolysaccharide & $22 / 228$ & 0.02490 \\
\hline GO:0030335 & Positive regulation of cell migration & $25 / 280$ & 0.02511 \\
\hline GO:0030111 & Regulation of Wnt signaling pathway & $21 / 214$ & 0.02515 \\
\hline GO:0060828 & Regulation of canonical Wnt signaling pathway & $17 / 152$ & 0.02544 \\
\hline GO:0051894 & Positive regulation of focal adhesion assembly & $6 / 18$ & 0.02978 \\
\hline GO: 1901890 & Positive regulation of cell junction assembly & $6 / 18$ & 0.02978 \\
\hline GO:0001937 & Negative regulation of endothelial cell proliferation & $7 / 27$ & 0.02978 \\
\hline
\end{tabular}

$\mathrm{B},(\mathrm{CDF}$ and $\mathrm{ACF})$ vs. MAF

\begin{tabular}{|c|c|c|c|}
\hline GO BP ID & Term & Overlap & Adjusted P-value \\
\hline GO:0048729 & Tissue morphogenesis & $44 / 358$ & 0.00023 \\
\hline GO:0051272 & Positive regulation of cellular component movement & $39 / 296$ & 0.00023 \\
\hline GO:0030198 & Extracellular matrix organization & $44 / 359$ & 0.00023 \\
\hline GO:0043062 & Extracellular structure organization & $44 / 360$ & 0.00023 \\
\hline GO:2000147 & Positive regulation of cell motility & $37 / 287$ & 0.00055 \\
\hline GO:0030335 & Positive regulation of cell migration & $36 / 280$ & 0.00068 \\
\hline GO:0048598 & Embryonic morphogenesis & $45 / 403$ & 0.00094 \\
\hline GO:0040017 & Positive regulation of locomotion & $37 / 304$ & 0.00118 \\
\hline GO:0030155 & Regulation of cell adhesion & $39 / 336$ & 0.00158 \\
\hline GO:0002009 & Morphogenesis of an epithelium & $35 / 296$ & 0.00312 \\
\hline GO:0048562 & Embryonic organ morphogenesis & $20 / 121$ & 0.00400 \\
\hline GO:0048704 & Embryonic skeletal system morphogenesis & $16 / 81$ & 0.00403 \\
\hline GO:0045785 & Positive regulation of cell adhesion & $24 / 171$ & 0.00507 \\
\hline GO:0036293 & Response to decreased oxygen levels & $30 / 245$ & 0.00507 \\
\hline GO:0009887 & Organ morphogenesis & $42 / 405$ & 0.00507 \\
\hline GO:0070482 & Response to oxygen levels & $31 / 259$ & 0.00516 \\
\hline GO:0071294 & Cellular response to zinc ion & $7 / 14$ & 0.00770 \\
\hline GO:0001666 & Response to hypoxia & $29 / 241$ & 0.00770 \\
\hline GO:0022617 & Extracellular matrix disassembly & $18 / 116$ & 0.01315 \\
\hline GO:0048705 & Skeletal system morphogenesis & $17 / 106$ & 0.01380 \\
\hline
\end{tabular}

The 'best' 20 ontology terms are provided for each comparison (i.e. corresponds to the terms with an adjusted P-value of the enrichment test $\geq 0.03$ ). GO BP, gene ontology biological process; MAF, melanoma-associated fibroblast; ACF, autologous control fibroblast; CDF, control dermal fibroblast. 

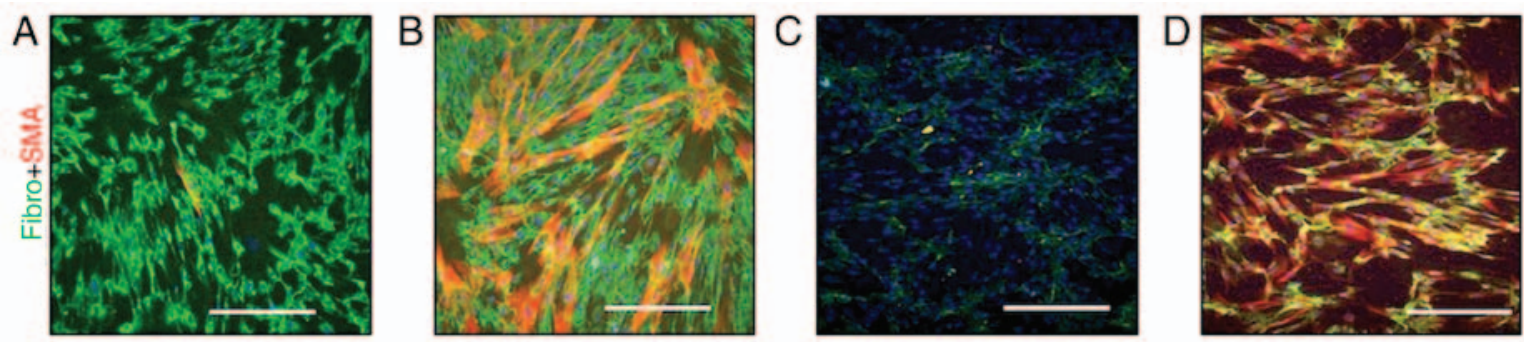

Figure 4. (A) Melanoma-associated fibroblasts exhibited fibronectin (green) in the cytoplasm and sporadic cells were SMA positive (red). (B) Autologous control fibroblasts with high incidence of SMA-positive myofibroblasts in a pool of autologous fibroblasts. (C) CDFs did not contain SMA-positive cells and produced only sparse fibro fibres. (D) Stimulation of CDFs by transforming growth factor- $\beta$ in culture mediaincreased transition of the fibroblasts to SMA-positive myofibroblasts, which also produced a dense fibro-positive extracellular matrix meshwork. Scale bar represents 50 mm. SMA, smooth muscle actin; fibro, fibronectin; $\mathrm{CDF}$, control dermal fibroblast.

$\mathrm{ACF}$ and $\mathrm{CDF}$ ). The raw data were preprocessed using GenomeStudio software to obtain methylated and unmethylated probe intensities, and the Bioconductor (20) package methylumi to background correct and normalize the data, and to calculate $\mathrm{M}$-values according to the following formula: $M=\log _{2}(($ methylated_probe_intensity +100$) /$ (unmethylated_ probe_intensity +100$)$ ). The positions of $\mathrm{CpG}$ islands were previously retrieved in human genomic DNA by Wu et al (23). $\mathrm{CpG}$ shores (and shelves) were defined as 2-kbp regions that flanked $\mathrm{CpG}$ islands (or shores, respectively).

Moderated t-test implemented in the limma package (19) was used to detect differentially methylated genomic regions (DMR) based on change in M-value and false discovery rate $(\mathrm{FDR}<0.1, \delta \mathrm{M}>1)$. PCA of the methylation data was performed using the made4 package on $\mathrm{M}$-values of regions that were considered DMR in at least one comparison.

The MIAME compliant expression and methylation data were subsequently deposited to the ArrayExpress database (accessions E-MTAB-4964 and E-MTAB-4965; https://www. ebi.ac.uk/arrayexpress/browse.html).

Gene set enrichment analysis (GSEA). GSEA was performed using Enrichr (24). Briefly, differentially expressed genes and differentially methylated genomic regions, respectively, that were specific for MAF or CDF were uploaded to the Enrichr web interface (http://amp.pharm.mssm.edu/Enrichr/). The analysis was performed with default parameters and with equal weight on each gene (or genomic region, in cases of methylation). Analysis of various gene set collections was performed, including the gene ontology (GO) terms and KEGG pathways, only the analysis of the GO terms, and in particular the biological process ontology, are reported. Other analyses resulted in the identification of similar gene sets. For expression data, the 20 best terms (i.e. those with the greatest significance) for each comparison are reported in Table II. The selection roughly corresponds to the terms with an adjusted $\mathrm{P}$-value of the enrichment test of $\mathrm{P}<0.03$. The analysis of DMRs did not result in any significantly enriched GO terms.

\section{Results}

Properties of fibroblasts isolated from the patients. Fibroblasts in cutaneous metastasis (Fig. 2A) exhibited SMA (Fig. 2B) and immunohistochemistry also revealed that melanoma cells in this metastasis were rich in TGF- $\beta 1$ (Fig. 2C). MAFs isolated from this metastasis were not harbouring the B-Raf V600E mutation (Fig. 3A). The isolated MAFs in culture exhibited a high cytoplasmic signal of fibronectin and were also sporadically positive for SMA (Fig. 4A).

This observation was in contrast with ACFs isolated from the normal skin of the same patient following 3 months on vemurafenib, where numerous clusters of SMA-positive myofibroblasts were present in vitro (Fig. 4B). The expression of fibronectin was similar in MAFs (Fig. 4A) and ACFs (Fig. 4B).

In the control experiment performed with CDFs, sparse extracellular fibres of fibronectin were observed, but no myofibroblasts were detected (Fig. 4C). As TGF- $\beta 1$ was detected in the melanoma metastasis and because the elevation of TGF- $\beta 1$ in sera of melanoma patients was documented previously (10), the effect of TGF- $\beta 1$ on CDFs was assessed. TGF- $\beta 1$ was able to markedly stimulate the transition of fibroblasts to myofibroblasts and also increase fibronectin production (Fig. 4D).

Comparison of expression profiles of MAFs, ACFs, and $C D F s$. The expression profiles of MAFs, ACFs and CDFs were compared using microarrays (Fig. 5A-D and Table I). The expression profiles differed between MAFs and ACFs in the expression of 1,800 genes, and between MAFs and CDFs there were 2,701 deregulated genes. Finally, there were 1,314 deregulated genes between ACFs and CDFs (FDR $<0.05$ ). Among the genes upregulated in the comparison of MAF and CDF cells, hyaluronan synthase 1 and desmoglein 2, which are both associated with extracellular matrix (ECM) formation, and cytokeratins 18 and 81 were identified. MAF cells exhibited decreased expression of chemokine CXCL12. In comparison of MAFs with ACFs, upregulation of hyaluronan synthase 1 and desmoglein 2 was observed, together with another ECM component, COL10A1. ACF showed upregulation of CXCL12 and cardiac-muscle and smooth-muscle actins (ACTC1 and ACTG2). ACTG2 was also upregulated in ACFs compared with CDFs, where the upregulation of the following Wnt-signalling pathway related genes was also observed: Frizzled family receptor 4 and naked cuticle homolog 2 .

Principal component analysis was performed to visualize associations between the analysed groups (Fig. 5A): The location of the groups in the plot and the number of deregulated genes between the groups demonstrated that ACFs differ greatly from CDFs. The association between $\mathrm{ACFs}$ and other analysed groups were further analyzed (Fig. 5B and C). Two 
A

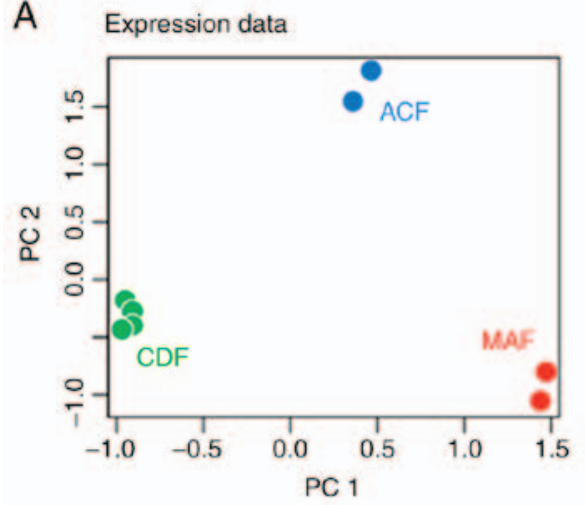

B
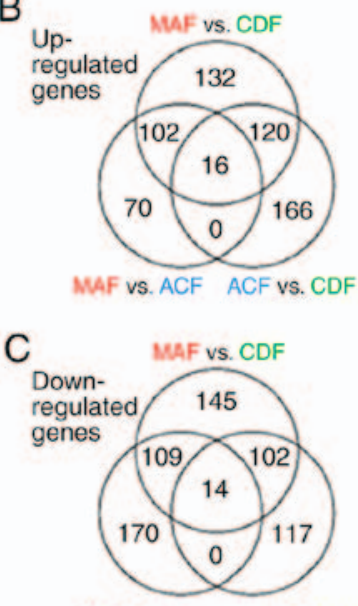

MAFvs. ACF ACFvs. CDF

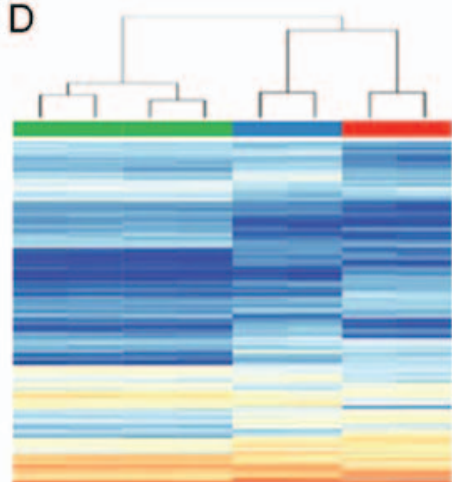

$=\mathrm{CDF}$

$=\mathrm{ACF}$

* MAF

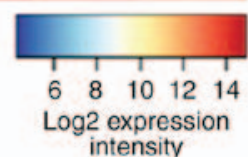

intensity
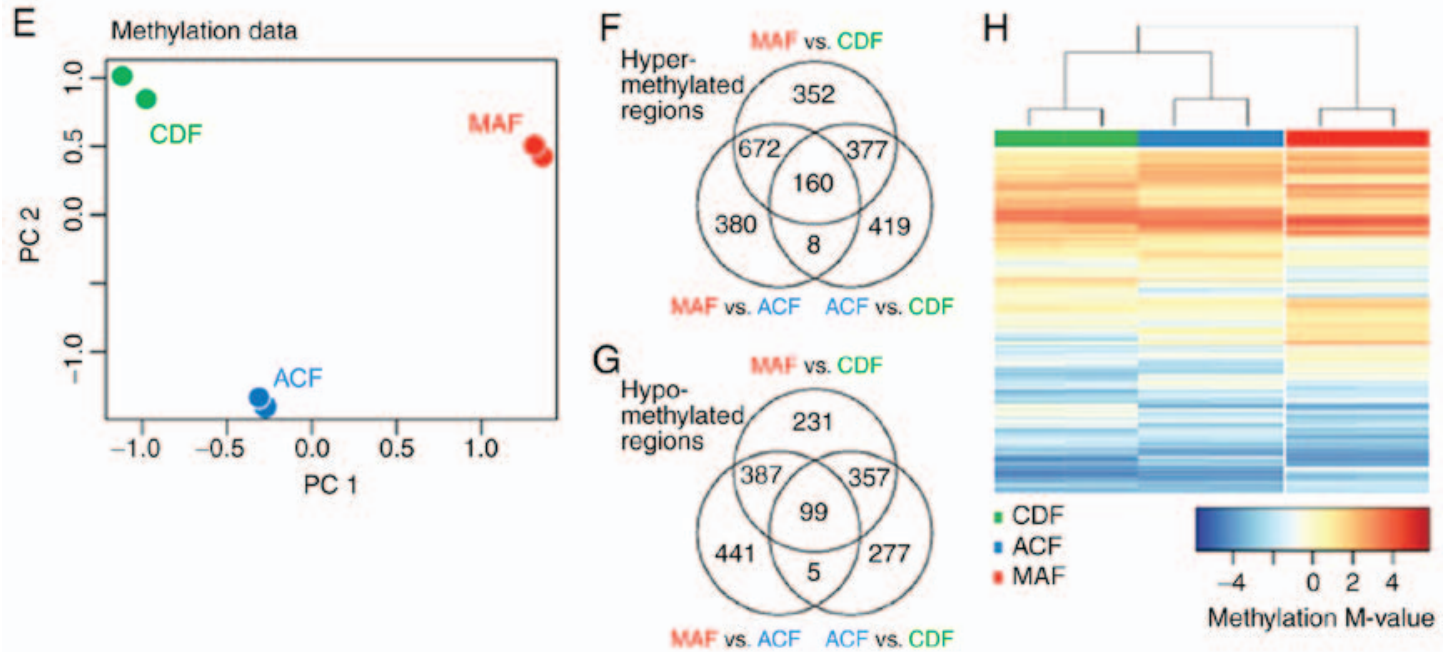

Figure 5. MAFs, ACFs and CDFs differ profoundly both in their gene expression profiles and in their genome methylation profiles. (A) Projections of the expression data on the first two PCs, as determined by a PC analysis performed on expression profiles of all differentially expressed genes. PC1 reflects differences between MAF and CDF, with ACF being placed between the stromal and normal fibroblasts. (B and C) Venn diagrams display overlaps of upregulated and downregulated genes. (D) Heatmaps with a comparative analysis of MAF, ACF and CDF present a clear separation of the different fibroblast groups both in their expression profiles. (E) Projections of the methylation data on the first two PCs were plotted as determined by a PC analysis performed on methylation profiles of all differentially methylated genes. ( $F$ and $\mathrm{G}$ ) Venn diagrams display overlaps of hyper-methylated and hypo-methylated regions in various studied comparisons. (H) MAF, ACF and CDF methylation profiles. Only differentially expressed genes and differentially methylated regions are presented. MAF, melanoma-associated fibroblast; ACF, autologous control fibroblast; $\mathrm{CDF}$, control dermal fibroblast; PC, principal component.

sets of deregulated genes were defined: a) Genes deregulated in both MAFs and ACFs, and in both MAFs and CDFs; and b) genes deregulated in both ACFs and CDFs, and in both MAFs and CDFs. To identify biological processes deregulated in a) MAFs and b) ACFs and MAFs, GSEA was performed on the respective sets (Table II).

Genes deregulated similarly in ACFs and in CDFs (in comparison with MAFs; set a) participate in control of biological processes related to cell migration and motility (GO:0051272, 2000147, 0030335 and 0048598), morphogenesis, ECM structure (GO:0048729, 0030198 and 0043062), and response to stress factors, including decreased oxygen level (GO:0070482, 0036293, 0071294 and 0001666). At the gene level, the activity of, e.g. CXCL12 and FGF13, were upregulated and was CXCL5 downregulated in ACFs and CDFs in comparison with MAFs.

ACFs share deregulated genes with MAFs (in comparison with CDFs; gene set b), which are associated with changes in angiogenesis and endothelial cell proliferation (GO:0001525, 0001936, 0001936, 0045765, 0045765, and 0001937), ECM structure (GO:0030198 and 0043062), response to wounding (GO:0002237), positive regulation of cell motility and locomotion (GO:2000147 and 0040017), ossification (GO:0001503), and regulation of the Wnt signaling pathway (GO:0030111 and 0060828). At the gene level, marked upregulation of interleukin (IL)6, VEGFA, and TGFB3 genes and downregulation of TGFA was observed in MAFs and ACFs as compared to CDFs. The relevant differentially regulated genes were consequently validated directly at the protein level, therefore quantitative-PCR was not used for validation.

Changes in DNA methylation in MAFs, ACFs and CDFs. To evaluate whether the changes in transcription activity of differently expressed genes were associated with epigenomic changes of the fibroblasts, differentially methylated genomic 


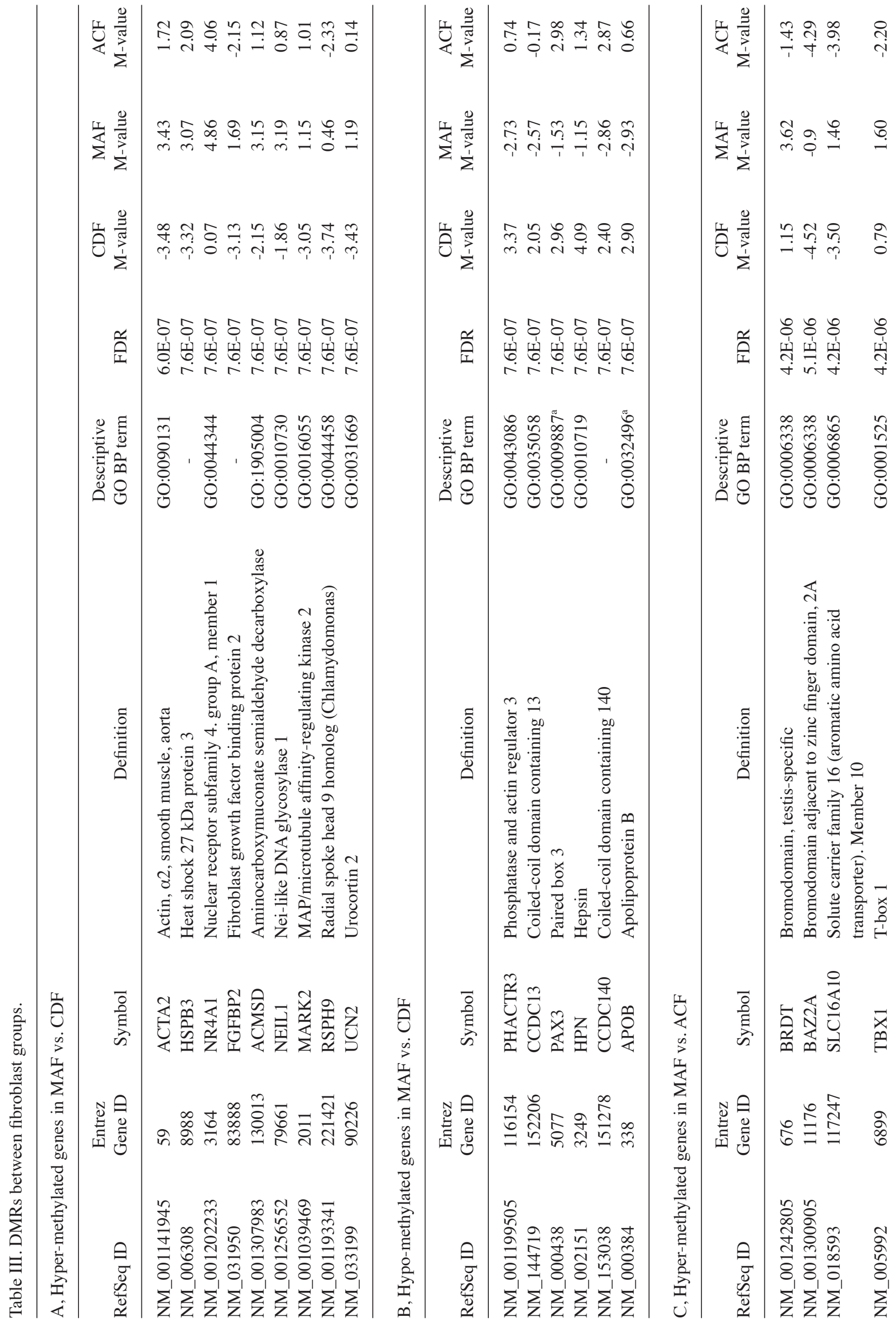




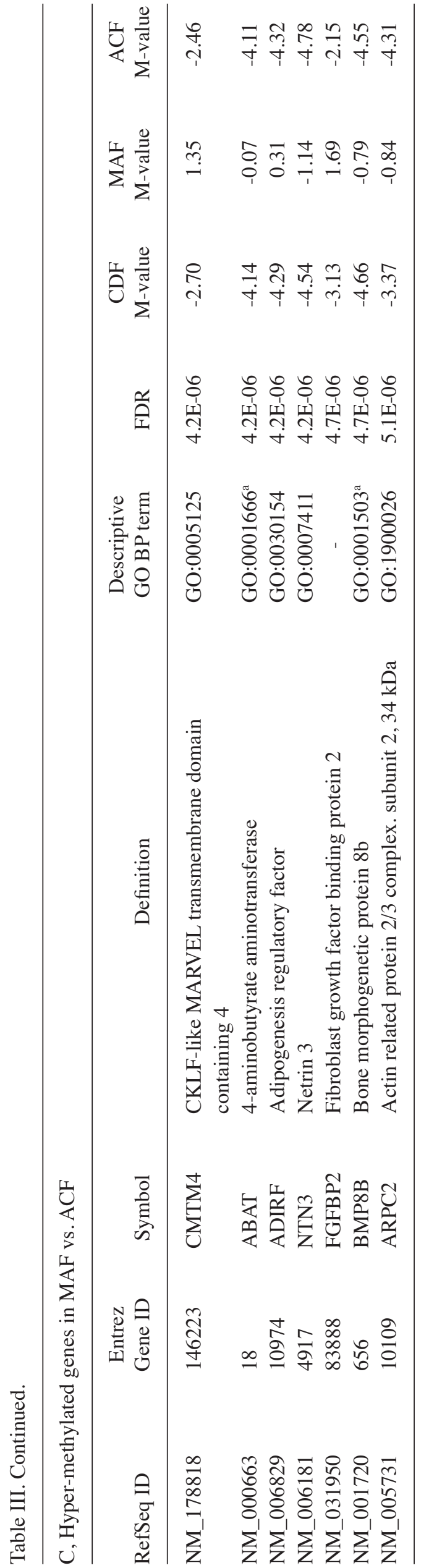

\begin{tabular}{|c|c|}
\hline 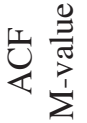 & 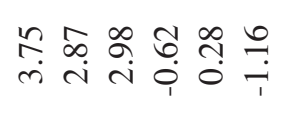 \\
\hline$\sum_{\substack{L \\
\sum}}^{\frac{0}{3}}$ & 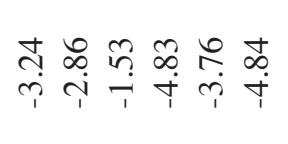 \\
\hline U & 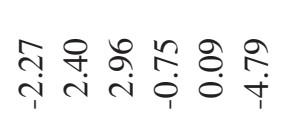 \\
\hline 公 & 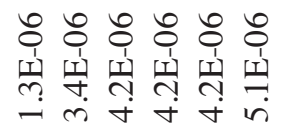 \\
\hline 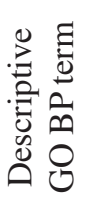 & 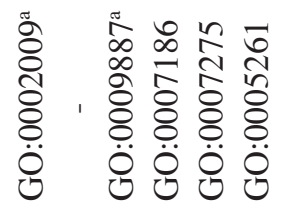 \\
\hline 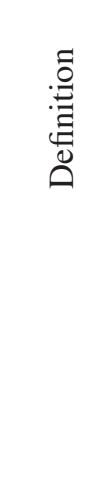 & 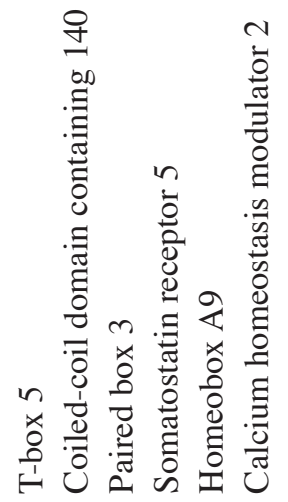 \\
\hline 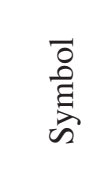 & 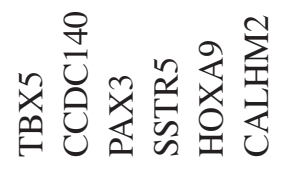 \\
\hline 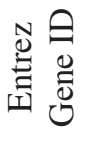 & 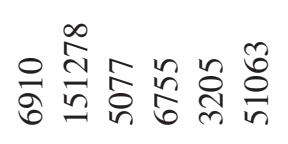 \\
\hline 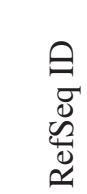 & 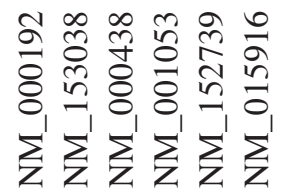 \\
\hline
\end{tabular}

\begin{tabular}{|c|c|}
\hline 㫐焉 & 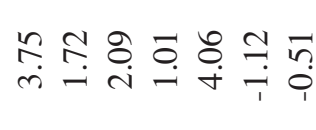 \\
\hline 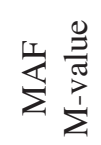 & 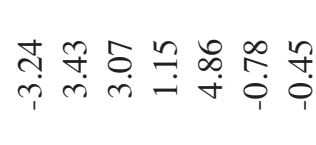 \\
\hline 已 & 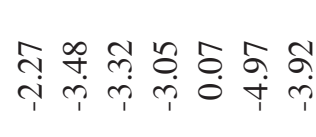 \\
\hline 品 & 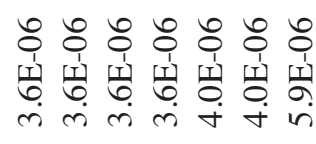 \\
\hline 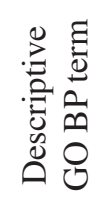 & 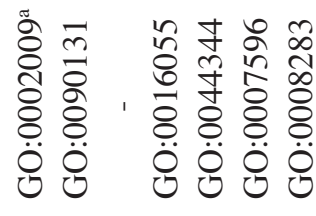 \\
\hline
\end{tabular}

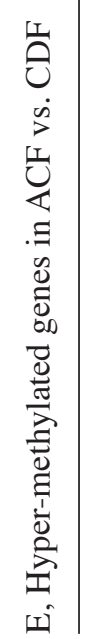

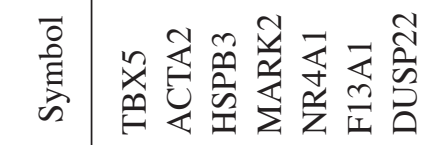

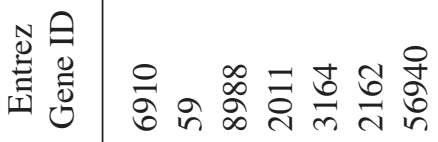

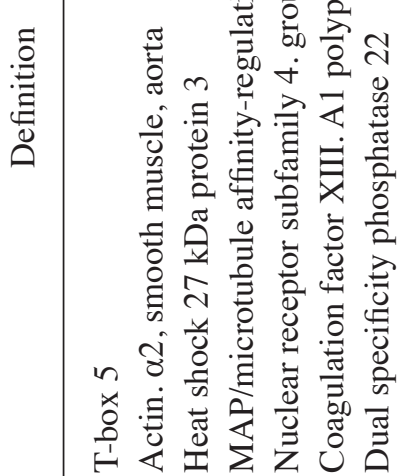

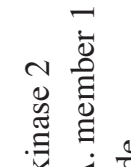
妾安

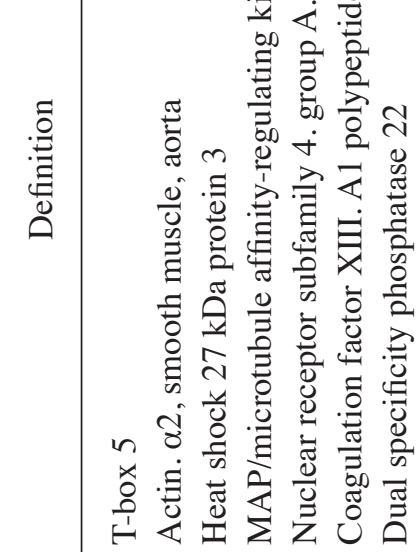




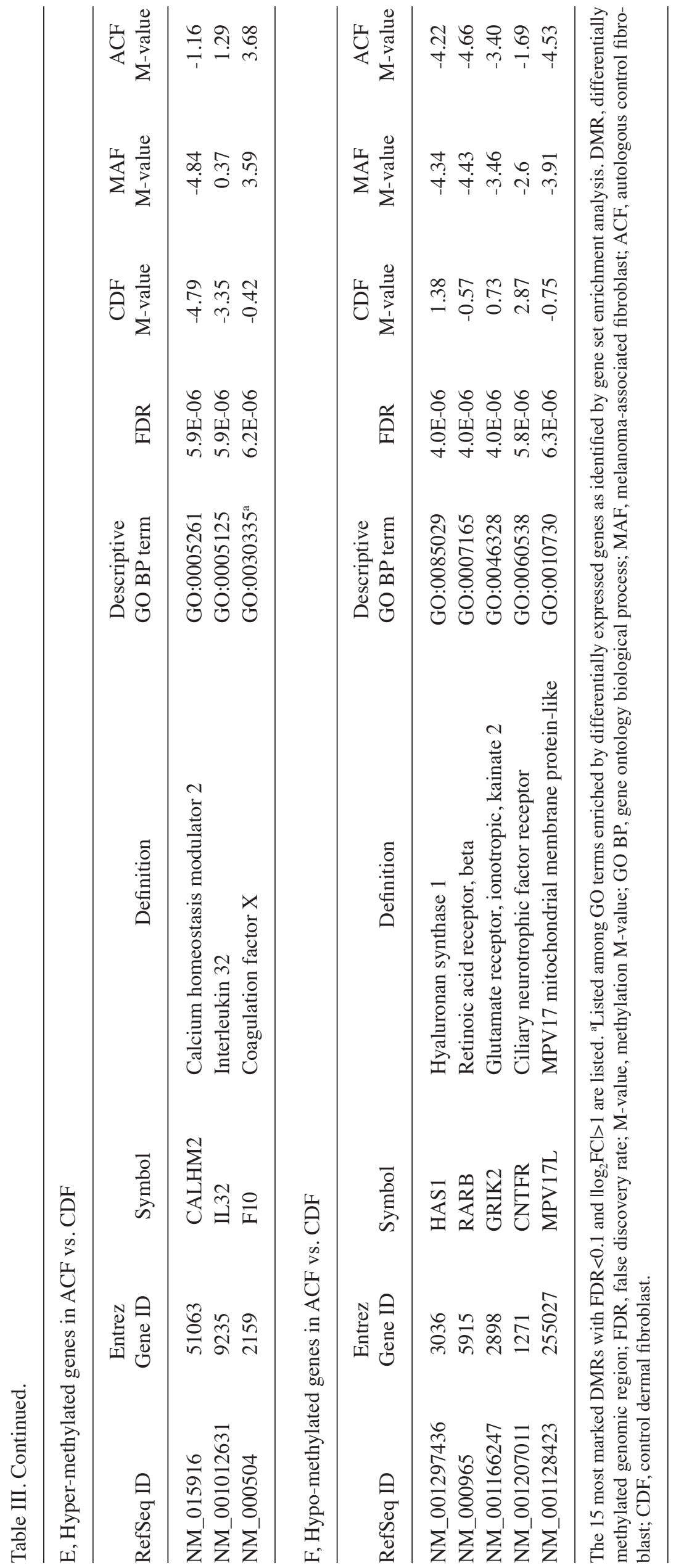



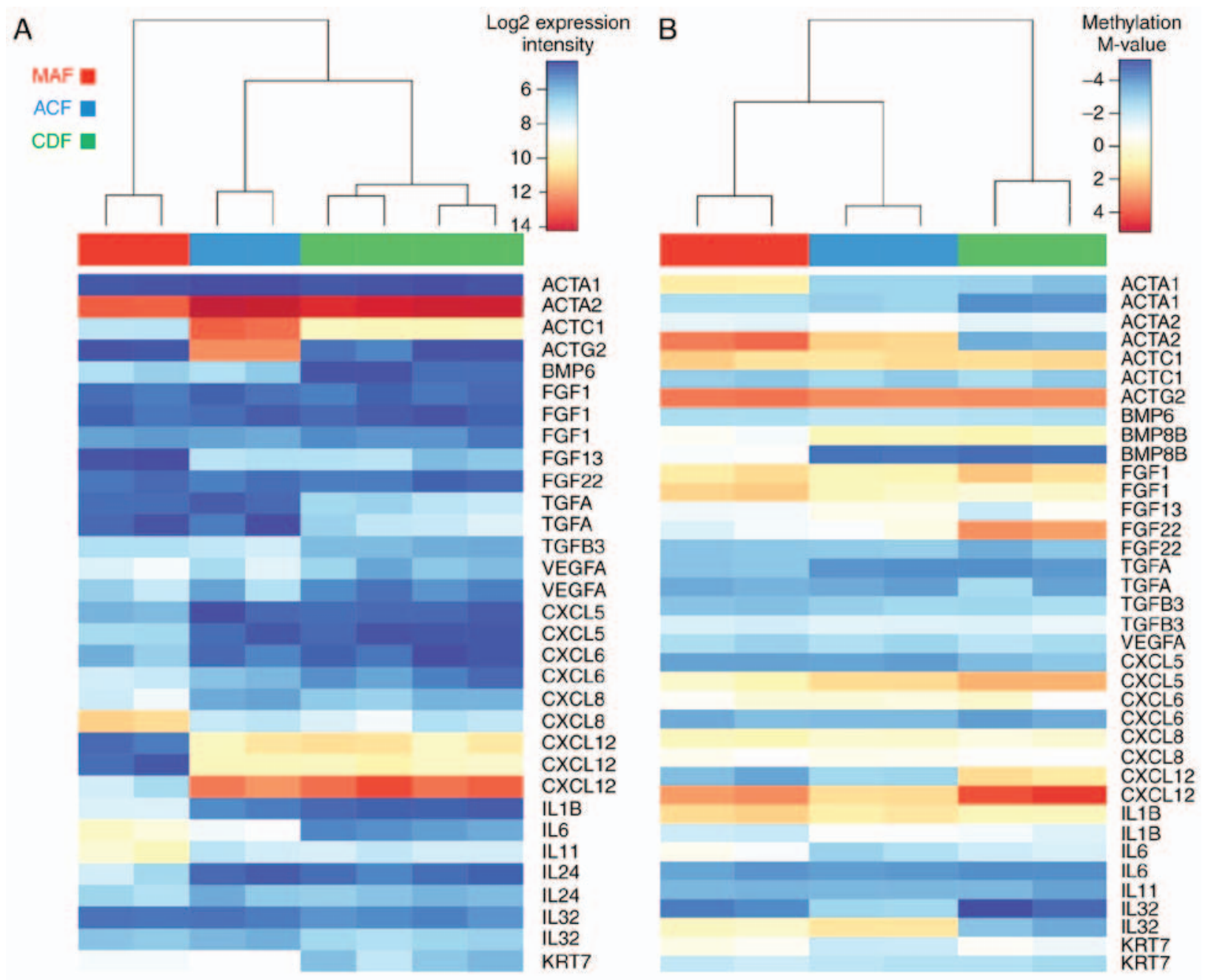

Figure 6. Changes in gene expression and methylation of selected genes with the strongest changes in gene expression and methylation. For the selected genes, heatmaps of (A) gene expression and (B) methylation of genomic regions overlapping the genes loci are presented. Methylation is expressed in terms of M-values. M=-4 [(A) 0; (B) 4] corresponds to 5\% [(A) 50\%; (B) 95\%] of the DNA in the methylated genomic region. MAF, melanoma-associated fibroblast; $\mathrm{ACF}$, autologous control fibroblast; $\mathrm{CDF}$, control dermal fibroblast.

regions (DMRs) were detected between the cultured fibroblasts using microarray technology. A total of 2,300 DMRs were detected between MAFs and ACFs (787 genes affected in $\mathrm{CpG}$ islands, 985 genes affected in $\mathrm{CpG}$ shores), between MAFs and CDFs there were 2,908 DMRs (966 genes affected in $\mathrm{CpG}$ islands, 1159 genes affected in $\mathrm{CpG}$ shores), and finally there were 1,835 DMRs between ACFs and CDFs (649 genes affected in $\mathrm{CpG}$ islands, 751 genes affected in CpG shores; FDR $<0.1, \mid \log \mathrm{FCl}>1$; Fig. $5 \mathrm{E}-\mathrm{H}$; Table III). PCA analysis (Fig. 5E) distinguished ACF cells from CDFs and indicated that they differ from either MAFs or CDFs, respectively (Fig. 5H). MAFs displayed hyper-methylation of genomic regions associated with an SMA (ACTA2) and fibroblast growth factor binding protein 2 (FGFBP2). The latter was specifically hyper-methylated in MAF cells. ACTA2 was hypo-methylated in normal CDF cells when compared with both MAF and ACF cells.

As in the gene expression analysis, the association between ACFs and other analysed groups was evaluated (Fig. 5F and G) and two sets of deregulated regions were defined: a) Those differentially methylated in both MAFs and ACFs, and MAFs and CDFs, and b) the genes differentially methylated in both
ACFs and CDFs, and MAFs and CDFs. GSEA was performed on the respective gene sets. Notably, although there is a large number of DMRs and associated genes, GSEA did not yield significant enrichment of any single GO term (except the general term 'behavior', which is unrelated to the studied phenomenon). Still, it was observed that the genes attributed to the GO terms affected by changes in gene transcription were widely present among DMRs. For MAF specific genes (set a), the GO terms typically contained 25 DMRs ( $\min 23$, max 70), with the exception of a single GO term (GO:0071294) with only 3 DMRs. For CDF specific genes (set b), the terms typically contained 17 DMRs (min 7, max 34), with the exception of the GO term GO:0001937 with two DMRs only. Therefore, it may be concluded that, although changes in methylation are not specifically targeted on biological processes manifested by changes in the expression activity, they target these processes to a large degree.

At the gene level, the largest changes in methylation of these selected genes were observed: Actins ACTA1 and ACTA2, the genes coding for SMA; growth factors FGF11, FGF22, and BMP8B; and chemokines and interleukins CXCL12, IL6, and IL32. 
Finally, the expression profiles (Fig. 6A) and methylation profiles (Fig. 6B) were evaluated, together with the selected genes with strongest changes in gene expression: Actins ACTC1 and ACTG2; growth factors FGF13, BMP6, and TGFA; chemokines and interleukins CXCL5, -6, -12, IL1B, IL6, IL8, IL11, and IL24; and keratin KRT7. Notably, the expression profiles of the selected genes in ACF samples are typically closer to expression profiles observed in CDF samples, whereas their methylation status is, in general, closer to MAFs (Fig. 6).

\section{Discussion}

In skin, normal fibroblasts represent a number of distinct differentiated mesenchymal cell types that have different origins, locations and functions $(25,26)$. Furthermore, similar heterogeneity is observed in tumor stromal tissues. The myofibroblast (27), which is a hallmark of cancer stroma, remains one of the most poorly understood cell types. It is clear that current understanding of the myofibroblast (its origins, functions and molecular regulation) will have a profound influence on the future effectiveness of regenerative medicine, tissue engineering and cancer therapy.

To exclude site-specific differences in e.g. gene transcription or DNA methylation, low passage fibroblasts obtained from the comparable anatomically defined region, the upper trunk, were used. Based on this restriction, relatively high homogeneity in gene transcription of CDFs, even from various donors, can be demonstrated.

In the present study, MAFs did not share B-Raf mutations with melanoma cells from skin metastasis. This suggests a likely local origin from the dermis, rather than the epithelial-to-mesenchymal transition from malignant cells. This also excludes MAFs as the primary target of the direct effect of B-Raf inhibitor.

Via the comparison of MAFs and CDFs from healthy donors, distinctive differences were observed. Recruitment of normal dermal cells in the vicinity of melanoma and their conversion to MAFs is classically associated with TGF- $\beta$ release from melanoma cells in a paracrine manner (27). Notably, ACFs from the same melanoma patient also greatly differed from CDFs from the general population. All gene expression profile differences were confirmed directly on the protein level, therefore omitting the necessity of quantitative-PCR.

The comparison of expression profiles of MAFs, ACFs and CDFs indicated that ACFs exhibit higher activity of the genes responsible for activation of fibroblasts and cancer cells, namely important mediators such as TGF- $\beta$ or IL6. ACFs also demonstrated deregulation of ACTG2 expression, and of another gene associated with smooth muscle, KCNMA1.

The presence of activated fibroblasts in normal dermis far from the melanoma lesions supports that melanoma is a systemic disease. This idea was initially proposed by Krasagakis et al (12). Furthermore, the present patient was treated with a B-Raf inhibitor which is known to induce cytokine release from melanoma cells in vitro (27). The observed unusual activation of ACF cells may be explained in a similar manner as activation of MAF via production of bioactive substances, namely TGF- $\beta$, IL6, IL8, and matrix metalloproteinase-1 by cancer cells in consequence to vemurafenib treatment (28-32).
TGF- $\beta$ signalling is one of the major pathways controlling cell and tissue behaviour in development and in various human pathologies. During tumorigenesis, TGF- $\beta$ has a dual role as tumor suppressor and tumor promoter (33). Important functions of this pathway have previously been described in a context-dependent manner both in epithelial cancer cells and in the tumor microenvironment during tumor progression $(28,30,33)$. The TGF- $\beta$ system signals via protein kinase receptors and SMAD mediators. Alterations of the TGF- $\beta$ signaling pathway are implicated in numerous types of human cancer (33).

Notably, differential expression of genes in the TGF- $\beta$ signalling pathway (e.g. SMAD molecules, etc.) have not been observed, despite the fact that the TGF- $\beta$ signalling pathway serves an important and key role in the tumor microenvironment and cancer progression. This reflects the dependence of SMADs on their phosphorylation status, rather than actual quantity. Furthermore, TGF- $\beta$ signalling is always reported as 'context-dependent' $(27,28,30)$. In such cases, the critical point is availability of the cytokine (TGF- $\beta$ ) in the tumor tissue.

In a recent study, Fedorenko et al (28) concluded that B-Raf inhibitor treatment escape in melanoma is due to short-term adaptation in which cells evade the immediate effects of the drug in the supportive microenvironment. However, confirmation of relevancy of this murine model for human pathology was (to the best of our knowledge) missing. The present study offers a comparison of this murine model to paired dermal fibroblasts isolated from a single melanoma patient prior to systemic therapy (B-Raf inhibitor) initiation and on treatment. Such paired material is rarely available and the present data is of relevance to the above-mentioned animal model.

The present data suggests a more sustained effect as the ACF cultures were stored without vemurafenib for a substantial duration ( $\geq 2$ months) during expansion in vitro. Maintenance of this activated phenotype would require more profound cellular changes, e.g. on the epigenetic level. Although dependence of the gene methylation and its expression is complex, and both gene upregulation and downregulation may occur with gene methylation (33), the observed increase of IL6 expression in ACFs may be associated with the observed demethylation of this gene in ACFs. Similarly, an increased expression of keratin 7 was observed in ACFs and MAFs accompanied by its decreased methylation. This unusual presence of simple type keratins in activated fibroblasts has also been described elsewhere (34).

Notably, observed upregulation of SMA expression in ACF cells at the protein level and the transcriptional activation of ACTA2, the gene coding for SMA, is consistent with abrupt hypermethylation of ACTA2 in both ACF and MAF cells. This observation may indicate the association of epigenetic changes in the activation of ACF cells.

Cancer-associated fibroblasts, including MAFs, produce numerous bioactive substances that actively influence cancer cell proliferation, differentiation and migration (15) and are able to strongly influence melanoma cells. Furthermore, cancer-associated fibroblasts, or MAFs specifically, are important drivers of tumor progression, including metastatic spread, and resistance to vemurafenib, as proposed recently $(27,30,37)$. Based on the presented similarities of MAFs and ACFs in the present patient on B-Raf inhibitor treatment, it may be hypothesized that 
vemurafenib therapy is able to influence not only B-Raf mutated tumor cells, but presumably may also shape the whole landscape of tissue microenvironment in the human body, to some extent. Vast differences have also been documented in control fibroblasts (ACF vs. CDF) on the level of DNA methylation, RNA transcription and also on the protein level. Such an activated microenvironment may be suitable for growth of circulating melanoma cells $(2,4,6)$. The fibronectin rich 'safe haven' may be created either by melanoma-associated fibroblasts or by distant fibroblasts activated by TGF- $\beta 1$ released from B-Raf therapy-stressed melanoma cells (27-31). Mechanistically, this phenomenon may participate in the induction of resistance to the therapy as depicted in the case of the presented patient.

The key question for the future is whether the present knowledge of fibroblast heterogeneity may be of clinical use in personalized cancer therapy. As indicated above, the ACFs resemble normal dermal fibroblasts of a healthy individual stimulated by TGF- $\beta 1$. Therefore, it may be hypothesized that therapeutic attenuation of TGF- $\beta$ activity $(38,39)$, blocking of transition of fibroblasts to myofibroblasts (39) and/or therapeutic blockade of their function (40) may be used to prevent resistance to B-Raf inhibitor therapy in the future. Mechanistically, this blockade would disrupt bi-directional cross-talk between the melanoma cells and stromal fibroblasts which allow the tumors to amplify a drug-resistant niche. Genomic studies have clearly demonstrated the evolution of genetic heterogeneity in melanoma in the course of tumor progression and metastasis formation $(41,42)$. The tumor microenvironment seems to participate in the tumor evolution by the formation of a suitable cellular ecosystem supporting its progression (43).

The present study represents a single clinical case analysis that may be easily linked to the latest development in preclinical melanoma research on animal models $(28-31,37,38)$. Larger cohort-based studies are necessary for the near future for selection of proper candidate additional targets for further improvement of personalized melanoma therapy.

\section{Acknowledgements}

The present study is a result of the project implementation: 'The equipment for metabolomic and cell analyses' (registration no. CZ.1.05/2.1.00/19.0400) supported by Research and Development for Innovations Operational Program (RDIOP) co-financed by the European Regional Development Fund and the state budget of the Czech Republic, MH CZ-DRO (Institute of Endocrinology grant no. EU 00023761). The present study was also supported by the Grant Agency of the Czech Republic (grant no. 16-05534S), the Ministry of Health (AZV nos. 16-29032A, 16-32665A and 16-30954A), Charles University (Project of Specific University Research grant nos. PRVOUK-27 and UNCE 23014) and by the Ministry of Education, Youth and Sports of CR within the National Sustainability Program II (Project BIOCEV-FAR reg. no. LQ1604) and by the project BIOCEV (grant no. CZ.1.05/1.1.00/02.0109). Access to computing and storage facilities owned by parties and projects contributing to the National Grid Infrastructure MetaCentrum were provided under the programme 'Projects of Large Research, Development, and Innovations Infrastructures' (grant no. CESNET LM2015042), is greatly appreciated. The present authors are grateful to Marie Jindráková for technical assistance and also to Ms. Pearl Harris for English language editing during manuscript preparation and consequent proofreading.

\section{Competing interests}

The authors declare that they have no competing interests.

\section{References}

1. Forsea AM, Del Marmol V, de Vries E, Bailey EE and Geller AC: Melanoma incidence and mortality in Europe: New estimates, persistent disparities. Br J Dermatol 167: 1124-1130, 2012.

2. Smetana K Jr, Dvoøánková B, Szabo P, Strnad H and Koláø M: Role of stromal fibroblasts in cancer originated from squamous epithelia. In: Dermal Fibroblasts: Histological perspectives, characterization and role in disease. Bai X. (ed). Nova Sciences Publishers, New York, NY, pp83-94, 2013.

3. Kulesa PM, Kasemeier-Kulesa JC, Teddy JM, Margaryan NV, Seftor EA, Seftor RE and Hendrix MJ: Reprogramming metastatic melanoma cells to assume a neural crest cell-like phenotype in an embryonic microenvironment. Proc Natl Acad Sci USA 103: 3752-3757, 2006.

4. Kodet O, Dvořánková B, Krejčí E, Szabo P, Dvořák P, Štork J, Krajsová I, Dundr P, Smetana K Jr and Lacina L: Cultivation-dependent plasticity of melanoma phenotype. Tumour Biol 34: 3345-3355, 2013.

5. Kodet O, Lacina L, Krejčí E, Dvořánková B, Grim M, Štork J, Kodetová D, Vlček C , Śáchová J, Kolář M, et al: Melanoma cells influence the differentiation pattern of human epidermal keratinocytes. Mol Cancer 14: 1, 2015.

6. Li L, Dragulev B, Zigrino P, Mauch C and Fox JW: The invasive potential of human melanoma cell lines correlates with their ability to alter fibroblast gene expression in vitro and the stromal microenvironment in vivo. Int J Cancer 125: 1796-1804, 2009.

7. Comito G, Giannoni E, Di Gennaro P, Segura CP, Gerlini G and Chiarugi P: Stromal fibroblasts synergize with hypoxic oxidative stress to enhance melanoma aggressiveness. Cancer Lett 324: 31-41, 2012.

8. Dvořánková $\mathrm{B}$, Szabo $\mathrm{P}$, Lacina $\mathrm{L}$, Kodet $\mathrm{O}$, Matoušková $\mathrm{E}$ and Smetana K Jr: Fibroblasts prepared from different types of malignant tumors stimulate expression of luminal marker keratin 8 in the EM-G3 breast cancer cell line. Histochem Cell Biol 137: 679-685, 2012.

9. Yin M, Soikkeli J, Jahkola T, Virolainen S, Saksela O and Hölttä E: TGF- $\beta$ signaling, activated stromal fibroblasts, and cysteine cathepsins B and L drive the invasive growth of human melanoma cells. Am J Pathol 181: 2202-2216, 2012.

10. Krasagakis K, Thölke D, Farthmann B, Eberle J, Mansmann U and Orfanos CE: Elevated plasma levels of transforming growth factor (TGF)-beta1 and TGF-beta2 in patients with disseminated malignant melanoma. Br J Cancer 77: 1492-1494, 1998.

11. Dvořánková B, Szabo P, Lacina L, Gal P, Uhrova J, Zima T, Kaltner H, André S, Gabius HJ, Sykova E and Smetana K Jr: Human galectins induce conversion of dermal fibroblasts into myofibroblasts and production of extracellular matrix: Potential application in tissue engineering and wound repair. Cells Tissues Organs 194: 469-480, 2011.

12. Krasagakis K, Garbe C, Schrier PI and Orfanos CE: Paracrine and autocrine regulation of human melanocyte and melanoma cell growth by transforming growth factor beta in vitro. Anticancer Res 14: 2565-2571, 1994.

13. Balch CM, Gershenwald JE, Soong SJ and Thompson JF: Update on the melanoma staging system: The importance of sentinel node staging and primary tumor mitotic rate. J Surg Oncol 104: 379-385, 2011.

14. Lacina L, Smetana K Jr, Dvoránková B, Pytlík R, Kideryová L, Kucerová L, Plzáková Z, Stork J, Gabius HJ and André S: Stromal fibroblasts from basal cell carcinoma affect phenotype of normal keratinocytes. Br J Dermatol 156: 819-829, 2007.

15. Kolář M, Szabo P, Dvořánková B, Lacina L, Gabius HJ, Strnad H, Sáchová J, Vlček C, Plzák J, Chovanec M, et al: Upregulation of IL-6, IL-8 and CXCL-1 production in dermal fibroblasts by normal/malignant epithelial cells in vitro: Immunohistochemical and transcriptomic analyses. Biol Cell 104: 738-751, 2012. 
16. Therasse P, Arbuck SG, Eisenhauer EA, Wanders J, Kaplan RS Rubinstein L, Verweij J, Van Glabbeke M, van Oosterom AT, Christian MC and Gwyther SG: New guidelines to evaluate the response to treatment in solid tumors. European organization for research and treatment of cancer, National Cancer institute of the United States, National Cancer Institute of Canada. J Natl Cancer Inst 92: 205-216, 2000.

17. Salvatore G, Chiappetta G, Nikiforov YE, Decaussin-Petrucci M, Fusco A, Carney JA and Santoro M: Molecular profile of hyalinizing trabecular tumours of the thyroid: High prevalence of RET/PTC rearrangements and absence of B-raf and N-ras point mutations. Eur J Cancer 41: 816-821, 2005.

18. Sykorova V, Dvorakova S, Ryska A, Vcelak J, Vaclavikova E, Laco J, Kodetova D, Kodet R, Cibula A, Duskova J, et al: BRAFV600E mutation in the pathogenesis of a large series of papillary thyroid carcinoma in Czech Republic. J Endocrinol Invest 33: 318-324, 2010.

19. Smyth GK: Linear models and empirical bayes methods for assessing differential expression in microarray experiments. Stat Appl Genet Mol Biol 3: Article 3, 2004.

20. Gentleman RC, Carey VJ, Bates DM, Bolstad B, Dettling M, Dudoit S, Ellis B, Gautier L, Ge Y, Gentry J, et al: Bioconductor: Open software development for computational biology and bioinformatics. Genome Biol 5: R80, 2004.

21. Valach J, Fík Z, Strnad H, Chovanec M, Plzák J, Cada Z, Szabo P, Sáchová J, Hroudová M, Urbanová M, et al: Smooth muscle actin-expressing stromal fibroblasts in head and neck squamous cell carcinoma: Increased expression of galectin-1 and induction of poor prognosis factors. Int J Cancer 131: 2499-2508, 2012.

22. Culhane AC, Thioulouse J, Perrière G and Higgins DG: MADE4: An $\mathrm{R}$ package for multivariate analysis of gene expression data. Bioinformatics 21: 2789-2790, 2005.

23. Wu H, Caffo B, Jaffee HA, Irizarry RA and Feinberg AP: Redefining $\mathrm{CpG}$ islands using hidden Markov models. Biostatistics 11: 499-514, 2010

24. Chen EY, Tan CM, Kou Y, Duan Q, Wang Z, Meirelles GV, Clark NR and Ma'ayan A: Enrichr: Interactive and collaborative HTML5 gene list enrichment analysis tool. BMC Bioinformatics 14: 128, 2013.

25. Driskell RR and Watt FM: Understanding fibroblast heterogeneity in the skin. Trends Cell Biol 25: 92-99, 2015.

26. Tomasek JJ, GAbbiani G, Hinz B, Chaponnier C and Brown RA: Myofibroblasts and mechano-regulation of connective tissue remodelling. Nat Rev Mol Cell Biol 3: 349-363, 2002.

27. Whipple CA and Brinckerhoff CE: BRAF(V600E) melanoma cells secrete factors that activate stromal fibroblasts and enhance tumourigenicity. Br J Cancer 111: 1625-1633, 2014.

28. Fedorenko IV, Wargo JA, Flaherty KT, Messina JL and Smalley KSM: BRAF inhibition generates a host-tumor niche that mediates therapeutic escape. J Invest Dermatol 135: 3115-3124, 2015.

29. Hirata E, Girotti MR, Viros A, Hooper S, Spencer-Dene B, Matsuda M, Larkin J, Marais R and Sahai E: Intravital imaging reveals how BRAF inhibition generates drug-tolerant microenvironments with high integrin $\beta 1 /$ FAK signaling. Cancer Cell 27: 574-588, 2015

30. Fedorenko IV and Smalley KS: The complexity of microenvironment-mediated drug resistance. Genes Cancer 6: 367-368, 2015.

31. De Wever O, Hendrix A, De Boeck A, Eertmans F, Westbroek W, Braems G and Bracke ME: Single cell and spheroid collagen type I invasion assay. Methods Mol Biol 1070: 13-35, 2014.
32. Varley KE, Gertz J, Bowling KM, Parker SL, Reddy TE, Pauli-Behn F, Cross MK, Williams BA, Stamatoyannopoulos JA, Crawford GE, et al: Dynamic DNA methylation across diverse human cell lines and tissues. Genome Res 23: 555-567, 2013.

33. Drabsch Y and ten Dijke P: TGF- $\beta$ signalling and its role in cancer progression and metastasis. Cancer Metastasis Rev 31: 553-568, 2012.

34. Guo L, Kuroda N, Nakayama H, Miyazaki E, Hayashi Y, Toi M, Hiroi M and Enzan H: Cytokeratin positive subserosal positive subserosal myofibroblasts in gastroduodenal ulcer; another type of myofibroblasts. Histol Histopathol 21: 697-704, 2006.

35. Seip K, Fleten KG, Barkovskaya A, Nygaard V, Haugen MH, Engesæter BØ, Mælandsmo GM and Prasmickaite L: Fibroblast-induced switching to the mesenchymal-like phenotype and $\mathrm{PI} 3 \mathrm{~K} / \mathrm{mTOR}$ signaling protects melanoma cells from BRAF inhibitors. Oncotarget 7: 19997-20015, 2016.

36. Johnson DB, Menzies AM, Zimmer L, Eroglu Z, Ye F, Zhao S, Rizos H, Sucker A, Scolyer RA, Gutzmer R, et al: Acquired BRAF inhibitor resistance: A multicenter meta-analysis of the spectrum and frequencies, clinical behaviour, and phenotypic associations of resistance mechanisms. Eur J Cancer 51: 2792-2799, 2015.

37. Llopiz D, Dotor J, Casares N, Bezunartea J, Díaz-Valdés N, Ruiz M, Aranda F, Berraondo P, Prieto J, Lasarte JJ, et al: Peptide inhibitors of transforming growth factor-beta enhance the efficacy of antitumor immunotherapy. Int J Cancer 125: 2614-2623, 2009.

38. Morris JC, Tan AR, Olencki TE, Shapiro GI, Dezube BJ, Reiss M, Hsu FJ, Berzofsky JA and Lawrence DP: Phase I study of GC1008 (fresolimumab): A human anti-transforming growth factor-beta (TGF $\beta$ ) monoclonal antibody in patients with advanced malignant melanoma or renal cell carcinoma. PLoS One 9: 90353, 2014.

39. Mifková A, Kodet O, Szabo P, Kučera J, Dvořánková B, André S, Koripelly G, Gabius HJ, Lehn JM and Smetana K Jr: Synthetic polyamine BPA-C8 inhibits TGF- $\beta 1$-mediated conversion of human dermal fibroblast to myofibroblasts and establishment of galectin-1-rich extracellular matrix in vitro. Chembiochem 15: 1465-1470, 2014.

40. Jobe NP, Rösel D, Dvořánková B, Kodet $\mathrm{O}$, Lacina L, Mateu R, Smetana K and Brábek J: Simultaneous blocking of IL-6 and IL-8 is sufficient to fully inhibit CAF-induced human melanoma cell invasiveness. Histochem Cell Biol 146: 205-217, 2016.

41. Harbst $\mathrm{K}$, Lauss M, Cirenajwis H, Winter C, Howlin J, Törngren T, Kvist A, Nodin B, Olsson E, Häkkinen J, et al: Molecular and genetic diversity in the metastatic process of melanoma. J Pathol 233: 39-50, 2014.

42. Patrick E, Schramm SJ, Ormerod JT, Scolyer RA, Mann GJ, Mueller S and Yang JY: A multi-step classifier addressing cohort heterogeneity improves performance of prognostic biomarkers in three cancer types. Oncotarget 8: 2807-2815, 2017.

43. Maley CC, Aktipis A, Graham TA, Sottoriva A, Boddy AM, Janiszewska M, Silva AS, Gerlinger M, Yuan Y, Pienta KJ, et al: Classifying the evolutionary and ecological features of neoplasms. Nat Rev Cancer 17: 605-619, 2017. 